\title{
Gamification and Consumer Loyalty: The Role of Utilitarian and Hedonic Benefit
}

\author{
Anam Shahid* and Sadia Arshad**
}

\begin{abstract}
Gamification is a trend of the future that primarily influences consumer behavior. This, in turn, triggers loyalty via a game-thinking loop. The multifold application of gamification, however, has remained a buzzword thus far, indicating an infancy of the game mechanics to impact consumer loyalty, and thinking patterns. In this regard, the gamification phenomenon encourages the mental and emotional engagement of the consumers. This subsequently can predict the magnitude, and the span of loyalty of the consumers as well. The current work, therefore, intends to empirically substantiate the impact of gamification on consumer loyalty, via two possible path-ways, i.e., gamification->hedonic benefits->consumer loyalty, and gamification->utilitarian benefits->consumer loyalty. Additionally, reward satisfaction is an aspect that is considered as a contingency variable in specifying the indirect impact of gamification on consumer loyalty. The sample for this study comprises of over 240 students from three private universities of Lahore, where data was collected with respect to the solicitation of gamification in online food applications. Results are shown to be positive and significant, thus supporting both the direct and indirect impacts of gamification on consumer loyalty. Moreover, an interaction term is also significant in ascertaining the positive conditional effects of reward satisfaction, on the direct path between gamification and consumer loyalty. The findings of the study provide valuable insight to consider gamification as an innovatively ambitious online marketing strategy for ensuring consumer loyalty.
\end{abstract}

Keywords: Gamification, utilitarian benefit, hedonic benefit, reward satisfaction, customer loyalty.

JEL Classification: M31, M37, L66, M39, O39.

\section{Introduction}

Gamification that has been adopted by firms primarily increases engagement, improves consumer loyalty, and builds a positive word-ofmouth among the potential and current consumers (Poncin et al., 2017).

\footnotetext{
${ }^{*}$ Research Scholar, Business Studies Department, Kinnaird College for Women, Lahore, Pakistan.

** Lecturer, Business Studies Department, Kinnaird College for Women, Lahore, Pakistan.
} 
Online food companies such as, FoodPanda, McDelivery and Carrefour have launched game applications as part of their loyalty programs to reward their consumers. Typically, consumers of a product or service use these applications for purchases that lead towards a game, where they earn bonus points as rewards in terms of free food, beverages, and discount coupons. In order to create an efficient and effective communication with their consumers, many companies incorporate game mechanics in their online applications/software, so as to deliver better brand related online experiences (Koivisto \& Hamari, 2019). It is, however, still unknown as to whether using gamified applications generate consumer loyalty in the Asian, specifically Pakistani, settings.

Even though the concept of gamification has a significant impact on consumer behaviour, marketing research lacks the adequate empirical evidence to substantiate the impact of gamification on consumer loyalty (Hofacker et al., 2016). Likewise, there is a scarcity of evidence to address this gap, which is what has been the inspiration behind the current study. In more specific terms, this paper introduces the utilitarian benefit and hedonic benefit, as a path between gamification and consumer loyalty; a direction that has been suggested by some of the recent work in this field (Hwang \& Choi, 2020). In order to complement the prior literature, this study reflects upon a holistic approach, primarily by signifying the empirical studies based on gamification, as a booming marketing tactic.

To present an in-depth understanding of gamification, we examine it under the realm of conventional constructs. Prior studies in this aspect contend the individuals' performance and behavior to be promoted by gamification. However, extensive exploration of consumer behavior in the realm of the gamification context is still at an early stage in academic research (Hawang \& Choi, 2020; Vitkauskaite et al., 2016). The current study has analyzed the influence of gamification in strengthening consumer loyalty via the incorporation of the hedonic and utilitarian benefits, so as to validate indirect possible path-ways in substantiating the game-thinking notion, and its overall application to the field of marketing.

Gamification encapsulates knowhow on several marketing concepts; services, ownership, brand awareness, purchase intention and motivation to name a few (Deterding, 2012; Huotari \& Hamari, 2012; Lucassen \& Jansen, 2014). Therefore, it is increasingly popular between the researchers and practitioners (Seaborn \& Fels, 2015). Also, typically, the satisfaction of receiving rewards makes consumers loyal towards gamified applications, as one of the flow dimensions includes the experience of 
being autotelic, by performing an activity in order to achieve these rewards (Faiola et al., 2013). It has been observed that gamification is becoming a critical aspect for marketing strategies, which if done correctly, can trigger powerful and real emotions of the human mind (Witt et al., 2011). Using game technology, with a smart approach tends to provide a better experience, by monitoring the consumer activities more effectively, and the gathering necessary information in order to improve the product competitiveness (Alčaković et al., 2017). Therefore, it can be affirmed that university students, selected as the target population, are more familiar with technology, and spend an additional amount of time accessing the internet on a daily basis (Hershatter \& Epstein, 2010). Moreover, they are also more likely to participate in activities for rewards and immediate gratification (Meister \& Willyerd, 2010).

Even though gamification has a significant impact on consumer behavior, the extant literature and research lacks adequate empirical evidence to substantiate the positive impact of gamification on consumer loyalty (Hofacker et al., 2016). Therefore, the current study is aimed towards empirically validating the relationship between gamification and consumer loyalty. In addition to this, as there is also a scarcity of evidence that addresses this gap, the current study introduces the utilitarian benefit and hedonic benefit, as a path between gamification and consumer loyalty. Also, Hamari \& Huotari (2017), through their well cited work, suggested and highlighted the need for further research based on the idea of gamification.

Gamification is a growing marketing trend, however, various concepts of marketing still need development. For instance, especially in terms of understanding the dynamics of consumer behavior towards the concept of gamification, there has been no conceptualization and depth in the research of how gamification, along with the impact of its benefits and rewards, leads towards consumer loyalty. Prior working on this discipline suggests that future research must investigate the mediating factors, such as the utilitarian or hedonic benefits, along with the other moderating factors for gamification based services that have been employed in this study (Hwang \& Choi, 2020). 


\section{Literature Review and Hypotheses}

\subsection{Gamification and Consumer Loyalty}

The concept of gamification is defined as, "taking essence of games, fun, play, transparency, design and challenge, and applying it to real world objectives rather than pure entertainment". It refers to a product and service design, delivering game like experiences for value creation and positive consumer responses (Huotari \& Hamari, 2017), in business contexts. Social media-based services often use gamification in order to encourage loyalty and improve the engagement of consumers (Jin, 2016).

Consumer loyalty is defined as, "commitment deeply held to repatronize, or rebuy a specific product or service constantly in future" (Oliver, 1999). In their study, Hamari et al. (2014) have displayed an understanding of the concept of gamification, in order to reinforce and affect consumer behavior. gamification shows its benefits in several domains; mainly in terms of retailing, mobile marketing, innovation, banking and human resource management services. Studies based on gamification literature have validated the concept of loyalty, as highlighted in the marketing and business domains (Helmefalk, 2019). In the context of these facts, it has thus been hypothesized that there is positive link between gamification and consumer loyalty.

Hypothesis 1: There is a positive and significant relationship between gamification and consumer loyalty.

\subsubsection{Gamification and Utilitarian Benefit}

An application incorporating gamification elements provides users with goals and feedback, which establish certain objectives and norms directing the experience of the users in gaining the relevant benefits (Leclercq et al., 2020). In this regard, the perceived benefits are divided into intrinsic (hedonic), and extrinsic (utilitarian) (Hsu \& Lin, 2016) categories. The utilitarian values aim to facilitate the users by motivating them and providing goals and feedback via the gamified apps (Huotari \& Hamari, 2017).

Gamified applications that are used by consumers, usually make them attain valuable and satisfying experiences (Holbrook, 2006), and it is the hedonic benefit that fulfills this experience profoundly.in conceptual terms, Huotari and Hamari (2017) emphasized upon the importance of gamification justified in a self-purpose nature of an activity, as people play games simply because they are "fun." According to Mathwick et al., (2001), 
visual appeal, entertainment, enjoyment and escapism are dimensions reflecting upon the value to escape the day-to-day world, further complementing the concept of hedonism. It can be affirmed that the younger generation is the most experience driven and emotional generation (Stein, 2013). This is primarily because they are constantly searching for purchases heard or read about, through external information, so as to enrich their emotional experience (Bathmanathan et al., 2018).

\subsubsection{Utilitarian Benefit and Consumer Loyalty}

Utilitarian benefits are mostly the, "tangible benefits that relate to utility, economy and efficiency" (Pallas et al., 2014). As a perceived utility, they acquire the capacity of service's informational and functional performance by maximizing its usefulness, accomplishment, performance and satisfaction, serving as utilitarian benefits for consumers using an application (Underwood \& Klein, 2002). In service literature, it can be observed that utilitarian benefits are derived by experiencing instrumental and functional support, from the elements that establish the objectives by directing the users towards realizing the benefits (Vargo \& Lusch, 2016). Hence, gaining benefits with utilitarian value determines the application's desired function, with the intent to be useful in achieving the expected results (Smith \& Colgate, 2007).

\subsubsection{Mediating Role of Utilitarian Benefit in Gamification-Consumer Loyalty Relationship}

With various interesting effects regarding the purchase, loyalty, increased engagement and retention of a particular brand or product, gamification has the potential to be a motivating marketing option (Hofacker et al., 2016). It is mostly resorted to in the case where certain applications serve an instrumental purpose, and provide utilitarian benefits to gain loyal consumers (Heijden, 2004). It must be noted that consumer loyalty is impacted by utilitarian values, with the ultimate goal to apply the elements of gamification in apps, in order to achieve certain benefits (Hsu \& Lin, 2016). Additionally, when a service application is gamified, it can either fall into the realm of 'fun' (hedonic, intrinsic), or provide a wanted outcome (utilitarian, extrinsic) (Ryan \& Deci, 2000). Research also reveals the extent by which gamification affects the loyalty of a user. This depends on their identified goals of meeting the perceived benefits, with the effect of the utilitarian benefit on the gamificationconsumer loyalty relationship that is to be stimulated if there is a match between the goal of the gamified app and the consumers' goal orientation 
(Higgins 2006). In the view of the above discussion, it can be hypothesized that a positive relationship between gamification and consumer loyalty is mediated by the utilitarian benefit as stated in the following hypothesis.

Hypothesis 2: Utilitarian benefit positively mediates the relationship between gamification and consumer loyalty.

\subsection{Hedonic Benefit and Consumer Loyalty}

Having fun, enjoying, feeling pleasure in something, and being entertained are actions and emptions that serve as hedonic benefits for the consumers using an application. This may also be referred to an individual's affective aspect (Luk \& Yip, 2008). The extant research often depicts the intention to use an entertainment system that is primarily predicted by enjoyment (Heijden, 2004). Hence, the intrinsically motivating nature of hedonic benefits drives the individuals' intensity to become loyal towards such activities in the future (Hogberg et al., 2019).

Prior studies have suggested companies to develop technologies that attract consumers, enhance interaction, and provide a memorable and fun experience, while communicating with them (Perryer et al., 2016). A user awarded with hedonic benefits satisfies their inner desire by pursuing a gaming element (Stock et al., 2015). Gamifying an experience brings unique hedonic value, which ultimately leads to a positive consumer behavior (Huotari \& Hamari, 2017), with an outcome of enjoyment (Hogberg et al., 2019). This is critical from a marketing perspective, especially in terms of its emotional aspects of consumption and association with the satisfaction of spending (Lemon \& Verhoef, 2016). Gamification exerts a positive effect when it comes to providing hedonic benefits as better predictors of loyalty (Zhao \& Guo, 2019). It is therefore proposed that hedonic benefit positively mediated the link between gamification and consumer loyalty in the following hypothesis.

Hypothesis 3: Hedonic benefit positively mediates the relationship between gamification and consumer loyalty.

\subsubsection{Moderating Role of Reward Satisfaction in Gamification - Consumer Loyalty Relationship}

The concept of reward satisfaction refers to, "satisfaction through an appetitive stimulus following through result from completion of performance and achievement of goals as; material, psychological and financial rewards" (De Gieter \& Hofmans, 2015). It generally befalls within 
the gamification literature as a tactic to motivate a more loyal behavior of users (Seaborn \& Fels, 2015). Moreover, game mechanics are clustered into; feedback in the form of bonuses, rewards, and progress by achieving points (Sigala, 2015). In this regard, the social exchange theory posits consumers to be motivated by specific future returns from their interactions (e.g., rewards), in exchange for loyalty and commitment (Shen et al., 2019).

Although a high level of gamification experience is known to be positively related to consumer loyalty (Landers et al., 2017), this relationship can be driven in a negative direction as well. Thus suggesting the presence of a moderating factor in the gamification-consumer loyalty relationship (Hwang \& Choi, 2020).

Reward satisfaction is a potentially powerful emotion that is believed to play its role as a partial moderator towards the gamificationconsumer loyalty linkage (Hogberg et al., 2019). It applies game mechanics to activities providing rewards, points, and prizes. This essentially stimulates more participation, attracts attention, increases engagement, and loyalty by completing a series of tasks leading to the promised rewards (Lamphun et al., 2019). The influence of gamification on consumer decision is primarily explained by the reward mechanisms that are developed. In this regard, the challenges, interactivity, assessment and social influence are factors that are taken into account when trending into this realm of consumer behavior (Temnyalov, 2019).

Satisfaction through rewards is one source to legitimize the concept of gamification (Amabile \& Kramer, 2011). The sheer satisfaction of getting rewards makes users feel more competent, by fulfilling their need for instant gratification. This then increases the incidence of loyalty and motivation (Jain \& Dutta, 2019) which can be applied in several domains as a practice to reward consumers for performing specific activities (Perryer et al., 2016). gamification in online applications is actively used as a marketing strategy, in order to generate loyalty with consumers' reward satisfaction. This is done by primarily predicting the effects of such applications, with reward programs being the most effective measure (Sailer et al., 2017). Therefore, taking all the aforementioned research together, it has been proposed that reward satisfaction can moderate the link between gamification and consumer loyalty in the following hypothesis.

Hypothesis 4: Reward satisfaction positively moderates the relationship between gamification and consumer loyalty. 


\subsection{Conceptual Model}

The proposed conceptual model aims to examine the gamification effects on consumer loyalty. Moreover, the current study is conducted to analyze the influence of consumer characteristics on effectiveness of marketing outcomes by gamification for consumer loyalty (Hofacker et al., 2016). This study incorporates the factors that are hedonic and utilitarian factors in nature to validate the research framework and compare the role of utilitarian and hedonic benefits in addressing this path. The abovementioned hypothesized relationships have been conceptualized in the conceptual model as shown in Figure-1.

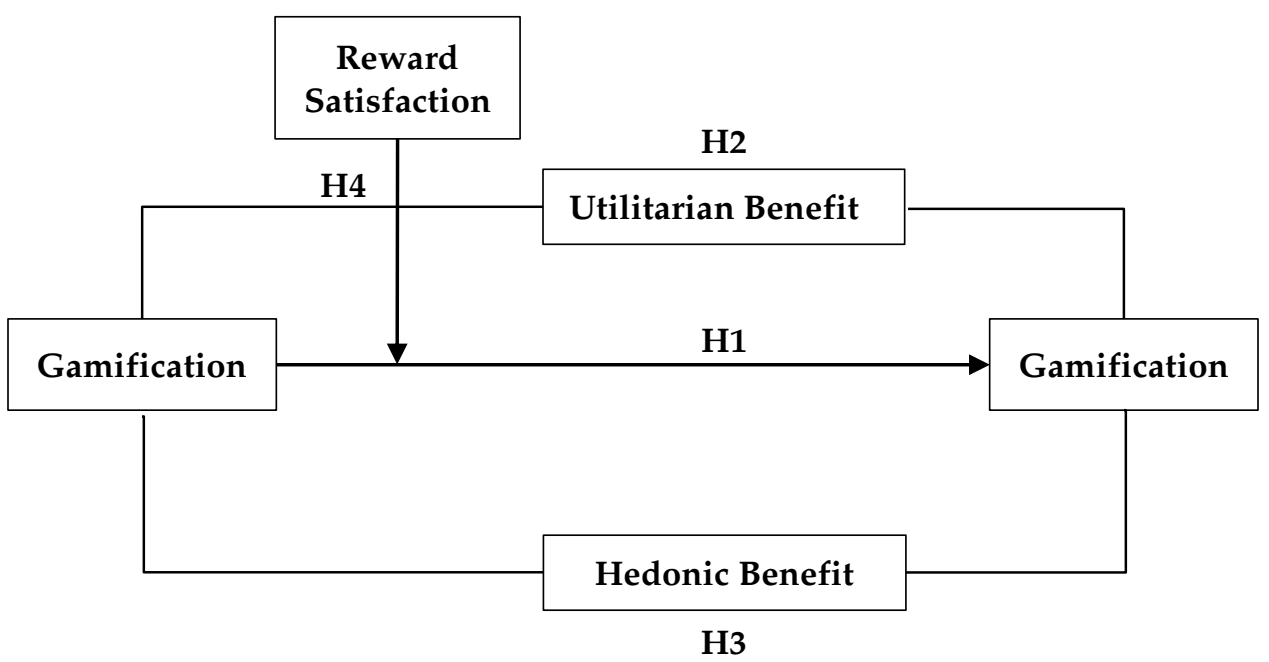

\section{Research Methodology}

Variables of interest were under investigation from past times, therefore descriptive research was conducted. Also, the research design resorted to the administration of a questionnaire, as single technique for data collection, hence the mono method quantitative research design was applied. Results have been generated into a quantitative analysis, and the data obtained is objective, which has helped to enhance findings and statistical comparisons. Moreover, the purpose of the study was also predicted, and was analytical in nature with a co-relational type of an investigation. Variables were defined and used in the prior research; therefore, no further exploration was required. Also, the research approach based on inductive reasoning as the hypotheses were formed on the basis of observation and the element of probability. Individuals as a unit of analysis with the category of the university were taken into account for an 
adequate amount of data, in order to generate reliable results. All the data was obtained in purely natural/ non-contrived settings. Furthermore, the interference of the researchers was minimal, with the first three lines of the questionnaire as simple, clear and precise in terms of the guidelines provided. In order to fulfill the specific objectives of this study, a crosssectional design was the opted time horizon.

\subsection{Sample}

The population for this study, and the sample were drawn on the basis of proper representation of the variables of interest. Young audience, being the most experience driven and emotional, often tend to search for purchases they heard or read about. This awareness could come through from an external source of information, and these individuals have a higher potential to be influenced by various online engagement tactics, including gaming (Bathmanathan et al., 2018). Hence, a sample of young adults, specifically university students has been drawn to generate a more reliable data.

University students from three universities in Lahore were offered to participate in the survey; Lahore College for Women University, University of Punjab, and FC College, and were taken as the target population. Finally, a sample of 240 students was drawn through the convenience sampling technique. Out of all the aged users of online food applications, university students were targeted, primarily because the younger audience is more prone towards technology, and is also well aware to seek bonuses, coupons, points, and easy to access applications to eat or shop with convenient access to the internet.

\subsection{Research Instrument}

For the purpose of this research, closed ended, self-administered survey questionnaires were considered to be the most suitable, so as to create the best fit between the research methodology and research purpose. The questionnaire collected responses from university students on campus, as well as online (by sending survey link), who have used online food applications, specifically Food Panda and McDelivery, which belong to the food and beverage industry. The full questionnaire is provided in the Annexure.

A Five-point Likert scale, anchored at $1=$ Strongly Disagree and $5=$ Strongly Agree, was used in the survey questionnaire, on the basis of past maturity scales, with slight modifications to suit the research context. Six 
questions from the Lamphun et al. (2019) scale were used to measure the incidence of gamification. Moreover, consumer loyalty was measured by five questions through the measurement scale adapted from Hung (2014). Then, the Utilitarian benefit has been measured from five questions that have been influenced from the existing measures developed by Wang (2017). In addition to this, the measurement scale for the hedonic benefit and reward satisfaction was adapted from Hamari \& Koivisto (2015), which included four questions for each of the considered variables, respectively.

\section{Data Analysis and Results}

\subsection{Characteristics of Sample}

The possible areas of diversity in the sample were identified through a demographic study. The analysis showed that $24.6 \%$ of the total sample fell below the age of 20 years, while $41.2 \%$ were between the age of $20-22$ years, and $6.5 \%$ in the age group of $23-25$ years. Moreover, $81.7 \%$ of the respondents were female, and $18.3 \%$ were male. The household income of $50.4 \%$ of the population was above $90,000,39.2 \%$ had an income spanning from $71,000-90,000,7.5 \%$ had an income between $51,000-70,000$, and $1.7 \%$ were with an income in the range of 30,000-50,000. Moreover, $60 \%$ of total sample size had a significant use of the apps of Food Panda and McDelivery, as their preferred online food application option. While $27.1 \%$ had a moderate extent of usage, and $12.9 \%$ had a small extent of usage of these apps. Out of the total population, 141 (59\%, N=141) students were from Kinnaird College for Women University, $58(24 \%, \mathrm{~N}=58)$ were from Forman Christian College, and $41(17 \%, N=41)$ were from the University of Punjab.

\subsection{Descriptive Statistics}

The descriptive statistics were generated by transforming raw data into interpretable facts that comprised of a range of variables, mean and standard deviation. The treatment of data for university students revealed that individuals belonging to the age group of 20 - 25 years had a mean value of 2.1, and a standard deviation of 0.87 . Also, household income with a range of 30,000 to 90,000 PKR and above had a mean value of 3.4, and standard deviation of 0.7 . The extent to which the respondents used online food application had a mean of 2.47, and a standard deviation of 0.71 . In addition to this, gamification had a mean value of 4 , and a standard deviation of 0.67 , showing that most of the sample were satisfied users of gamified food applications. Furthermore, consumer loyalty had a mean value of 4.1, and a 
standard deviation of 0.60 . Also, the mediators (utilitarian and hedonic benefit) had mean values of 4.0 and 4.1 , respectively. This depicted that a major portion of the sample was perceived to have an above average to high level of both benefits, with standard deviations 0.62 and 0.71 respectively. Moving on, the moderator, reward satisfaction had a mean value 4.1, showing that the sample had an above average, and high satisfaction with the rewards while using gamified food applications, with a standard deviation of 0.62 . All the descriptive elements pertaining to the findings have been summarized in Table 1 .

Table: 1: Descriptive Statistics

\begin{tabular}{lcc}
\hline Variables & Mean & Standard Deviation \\
\hline Age & 2.1 & 0.87 \\
Household Income & 3.4 & 0.70 \\
User Extent & 2.5 & 0.71 \\
Gamification & 4.0 & 0.67 \\
Consumer Loyalty & 4.1 & 0.60 \\
Utilitarian Benefit & 4.0 & 0.62 \\
Hedonic Benefit & 4.1 & 0.71 \\
Reward Satisfaction & 4.1 & 0.62 \\
\hline
\end{tabular}

\subsection{Reliability Analysis}

A reliability analysis was also calculated through the statistical treatment of the raw data, by considering the value of the Cronbach Alpha. All the variables showed excellent reliability values (i.e., $\alpha>0.7$ ), as summarized in Table 2.

Table: 2: Reliability Statistics

\begin{tabular}{lcc}
\hline Variables & Items & Cronbach's alpha- $\boldsymbol{\alpha}$ \\
\hline Gamification & 6 & 0.887 \\
Consumer Loyalty & 5 & 0.858 \\
Utilitarian Benefit & 4 & 0.836 \\
Hedonic Benefit & 5 & 0.952 \\
Reward Satisfaction & 4 & 0.813 \\
\hline
\end{tabular}

\subsection{Factor Loadings}

The factor analysis has been done to verify the percentages of the variance accounted for each factor, corresponding to the variables of the study. It can be observed that all the factor loadings range from 0.06 to 0.09 , 
which happens to be above the minimum acceptable value of 0.06 , thus compelling for a further analysis on the basis of sufficient factorability.

Table: 3: Factor Loadings

\begin{tabular}{|c|c|c|c|c|c|c|}
\hline Construct & Items & & & $\begin{array}{c}\text { Factor } \\
\text { loadings }\end{array}$ & & \\
\hline \multirow[t]{6}{*}{ Gamification } & Gam1 & 0.891 & & & & \\
\hline & Gam2 & 0.721 & & & & \\
\hline & Gam3 & 0.683 & & & & \\
\hline & Gam4 & 0.830 & & & & \\
\hline & Gam5 & 0.768 & & & & \\
\hline & Gam6 & 0.875 & & & & \\
\hline \multirow{4}{*}{$\begin{array}{l}\text { Utilitarian } \\
\text { Benefit }\end{array}$} & U_ben1 & 0.921 & & & & \\
\hline & U_ben2 & & 0.890 & & & \\
\hline & U_ben3 & & 0.937 & & & \\
\hline & U_ben4 & & 0.901 & & & \\
\hline \multirow{5}{*}{$\begin{array}{l}\text { Hedonic } \\
\text { Benefit }\end{array}$} & H_ben1 & & & 0.768 & & \\
\hline & H_ben2 & & & 0.897 & & \\
\hline & H_ben3 & & & 0.690 & & \\
\hline & H_ben4 & & & 0.676 & & \\
\hline & H_ben5 & & & 0.741 & & \\
\hline \multirow{4}{*}{$\begin{array}{l}\text { Reward } \\
\text { Satisfaction }\end{array}$} & R_sat1 & & & & 0.841 & \\
\hline & R_sat2 & & & & 0.680 & \\
\hline & R_sat3 & & & & 0.876 & \\
\hline & R_sat4 & & & & 0.910 & \\
\hline \multirow{5}{*}{$\begin{array}{l}\text { Consumer } \\
\text { Loyalty }\end{array}$} & Con_loy1 & & & & & 0.771 \\
\hline & Con_loy2 & & & & & 0.863 \\
\hline & Con_loy3 & & & & & 0.810 \\
\hline & Con_loy4 & & & & & 0.791 \\
\hline & Con loy5 & & & & & 0.803 \\
\hline
\end{tabular}

\subsection{Confirmatory Factor Analysis}

The composite reliability values (CR) of the all the study variables falls above the minimum threshold value of 0.06 . This, thus validates the indicators from the same construct that substantiated convergent validity. Furthermore, the maximum shared variance (MSV) for all the variables taken into consideration also fall in less than the average variance extracted (AVE), which validated the discriminant validity. 
Table: 4: Confirmatory Factor Analysis Model Fitness Comparisons

\begin{tabular}{llccccccc}
\hline & Model & $\chi^{2} / \mathbf{d f}$ & TLI & CFI & RMSEA & SRMR & SRMRw & SRMRb \\
\cline { 2 - 8 } Alternative & One Factor 4.241 & 0.801 & 0.822 & 0.232 & 0.089 & & \\
Measurement & Two & 4.269 & 0.838 & 0.912 & 0.215 & 0.037 & & \\
Models & Factor & & & & & & & \\
& $\begin{array}{l}\text { Three } \\
\text { Factor }\end{array}$ & 0.172 & 0.910 & 0.976 & 0.269 & 0.041 & & \\
& Four & 1.563 & 0.932 & 0.970 & 0.086 & & 0.003 & 0.148 \\
& Factor & & & & & & & \\
& Five & 0.825 & 0.964 & 0.987 & 0.025 & & 0.002 & 0.251 \\
\hline
\end{tabular}

Notes: $\chi 2=$ Chi-square; $\mathrm{df}=$ Degrees of Freedom; TLI= Tucker-Lewis Coefficient; CFI= Comparative Fit Index; RMSEA= Root Mean Square Error of Approximation; SRMRw= Standardized Root Mean Square Residual Within; SRMRb= Standardized Root Mean Square Residual Between

The model fitness has been validated by using the confirmatory factor analysis (CFA). In order to assess the comparative fitness of hypothesized model, the Root Mean Square Error Approximation (RMSEA), along with Comparative Fit Index (CFI) and Tucker Lewis Index (TLI) has been taken into account. The acceptable limit for these indices is $\leq 0.08$ for RMSEA, and SRMR within and between $>0.90$ for TLI, and CF and $<2$ for the Chi-Square/Degrees of Freedom (Pavlov et al., 2019). Accordingly, the proposed (five factor model) exhibits the superior fit indices over the alternative models.

\subsection{Composite Reliability and Scale Validity}

The composite reliability values (CR) of the research variables falls above the minimum threshold value of 0.06 , thus validating the indicators from the same construct that substantiated convergent validity. Furthermore, the maximum shared variance (MSV), for all the variable also falls between less than the average variance extracted (AVE), which validated the discriminant validity. 
Table: 5: Composite Reliability and Scale Validity

\begin{tabular}{lcccc}
\hline & Composite Reliability \& Validity & & & \\
\hline & CR & AVE & MSV \\
\hline Gamification & 0.718 & 0.792 & 0.699 \\
Utilitarian Benefit & 0.789 & 0.812 & 0.587 \\
Hedonic Benefit & 0.761 & 0.891 & 0.620 \\
Reward Satisfaction & 0.890 & 0.901 & 0.542 \\
Consumer Loyalty & 0.852 & 0.920 & 0.681 \\
\hline
\end{tabular}

Notes: $\mathrm{CR}=$ Composite Reliability; $\mathrm{AVE}=$ Average Variance Extracted; $\mathrm{MSV}=$ Maximum Shared Variance

\subsection{Correlation Matrix}

A very careful and tedious tabulation of the facts and figures generated a correlation matrix, in order to find the hypothesized relation's initial support, as showed in Table 6.

Table: 6: Correlation Matrix

\begin{tabular}{lccccc}
\hline Variables & $\mathbf{1}$ & $\mathbf{2}$ & $\mathbf{3}$ & $\mathbf{4}$ & $\mathbf{5}$ \\
\hline 1.Gamification & 1 & & & & \\
2. Consumer Loyalty & $0.767^{* *}$ & 1 & & & \\
3. Utilitarian Benefit & $0.759^{* *}$ & $0.770^{* *}$ & 1 & & \\
4. Hedonic Benefit & $0.736^{* *}$ & $0.671^{* *}$ & $0.701^{* *}$ & 1 & \\
5. Reward Satisfaction & $0.720^{* *}$ & $0.707^{* *}$ & $0.774^{* *}$ & $0.671^{* *}$ & 1 \\
\hline
\end{tabular}

$\mathrm{n}=240,{ }^{* *}$ Correlation is significant at the 0.01 level (2-tailed)

Consumer loyalty showed a significant and positive association with gamification $(\mathrm{r}=0.767, \mathrm{p}<0.01)$, thus evidencing an increase in the usage of applications with game elements, in order to predict greater consumer loyalty. This fact is congruent with various early studies based on the gamification-consumer loyalty relationship (Poncin et al., 2017). Moreover, the utilitarian and hedonic benefit have positive, significant relationships with the consumer loyalty $(\mathrm{r}=0.770, \mathrm{p}<0.01)(\mathrm{r}=0.671$, $\mathrm{p}<0.01)$ respectively. Also, the reward satisfaction showed a significant and positive relationship with gamification $(\mathrm{r}=0.720, \mathrm{p}<0.01)$, and a positive relationship with consumer loyalty $(\mathrm{r}=0.707, \mathrm{p}<0.01)$. This validated the fact that moderator reward satisfaction is powerful enough to alter the level of gamification and consumer loyalty. 


\subsection{Hypotheses Testing}

In order to test the hypotheses statements, the mediation and moderation analyses, Model 5 and Model 4, as described in PROCESS Hayes with bootstrap methods, were performed. Model 5 was performed in order to test the significant relationship between gamification and consumer loyalty, with a mediating effect of the utilitarian benefit and moderating effect of the reward satisfaction.

\subsubsection{Gamification-Consumer Loyalty Relationship}

The detailed tabulation of the results in Table 7 interpret that the positive values of the lower level of confidence interval are (LLCI=0.221), and the upper level of confidence interval are (ULCI=0.612), while the coefficient $\beta$ equals 0.417 , and the $p$ value is $0.001<0.10$. This shows a significant relationship between gamification and consumer loyalty, thus supporting Hypothesis 1.

\subsubsection{Mediating Role of Utilitarian Benefit in Gamification-Consumer Loyalty Relationship}

In order to test the mediating effect of the utilitarian benefit in the gamification-consumer loyalty relationship, the significance of the independent variable, on the mediator, is tested first. The results show that gamification has a positive and significant relationship with the utilitarian benefit, at a value of 0.708 (95\% CI [0.643, 0.773]). Alongside this, the linkage between the utilitarian benefits and the dependent variable is also found to be significant, i.e., the utilitarian benefits->customer loyalty 0.344 $(95 \%$ CI $[0.239,0.448])$. Finally, the mediation effects of the utilitarian benefits, on the indirect effects of gamification, on customer loyalty are also significant, i.e., gamification-> utilitarian benefits->consumer loyalty 0.234 (95\% CI $[0.142,0.337])$. Thus, the results support hypothesis 2.

\subsubsection{Moderating Role of Reward Satisfaction in Gamification-Consumer Loyalty Relationship}

The interaction between gamification and Reward satisfaction is statistically significant at a value of 0.018 (95\% CI [0.064, 0.027]. this predicts that the variable of reward satisfaction positively moderates the path between gamification and consumer loyalty, thus supporting Hypothesis 4 (Reward satisfaction moderates the relationship between gamification and consumer loyalty). Hence the results showed that reward 
satisfaction, with the interaction of gamification to generate higher consumer loyalty, supports hypothesis 4 . (For details, please see Table 7)

Table: 7: Results for Hypotheses (1, 2 and 4)

\begin{tabular}{|c|c|c|c|c|c|c|c|}
\hline $\begin{array}{l}\mathrm{Y}=\text { CUSTL } \\
\mathrm{X}=\mathrm{GAMI} \\
\mathrm{M}=\mathrm{UTIB} \\
\mathrm{W}=\text { REWS } \\
\text { Sample } \mathrm{Si}\end{array}$ & & & & & & & \\
\hline Outcome: & & & & UTIB & & & \\
\hline Model & & & & umma & & & \\
\hline & $\begin{array}{c}\mathbf{R} \\
0.76\end{array}$ & $\begin{array}{c}\text { R-Sq } \\
0.58\end{array}$ & $\begin{array}{c}\text { MSE } \\
0.16\end{array}$ & $\begin{array}{c}\mathbf{F} \\
322.87\end{array}$ & $\begin{array}{l}\text { dff1 } \\
1.00\end{array}$ & $\begin{array}{c}\mathbf{d f} \mathbf{2} \\
238.00\end{array}$ & $\begin{array}{c}\mathbf{p} \\
.000\end{array}$ \\
\hline Model & & & & úmma & & & \\
\hline & & coeff & se & $t$ & $p$ & LLCI & ULCI \\
\hline Constant & & 1.22 & 0.16 & 7.66 & .000 & 0.96 & 1.48 \\
\hline GAMI & & 0.71 & 0.04 & 17.96 & .000 & 0.64 & 0.77 \\
\hline Outcome: & & & & CUSTL & & & \\
\hline Model: & & & & Summa & & & \\
\hline & $\begin{array}{c}\mathbf{R} \\
0.82\end{array}$ & $\begin{array}{c}\text { R-Sq } \\
0.68\end{array}$ & $\begin{array}{c}\text { MSE } \\
0.12\end{array}$ & $\begin{array}{c}\mathbf{F} \\
124.94\end{array}$ & $\begin{array}{l}\text { df1 } \\
4.00\end{array}$ & $\begin{array}{c}\text { df2 } \\
235.00\end{array}$ & $\begin{array}{c}\mathbf{p} \\
.000\end{array}$ \\
\hline Model & & & & umma & & & \\
\hline & & coeff & se & $t$ & $\mathrm{p}$ & LLCI & ULCI \\
\hline Constant & & 0.48 & 0.35 & 1.38 & .167 & 0.09 & 1.06 \\
\hline GAMI & & 0.42 & 0.12 & 3.51 & .001 & 0.22 & 0.61 \\
\hline UTIB & & 0.34 & 0.06 & 5.41 & .000 & 0.24 & 0.45 \\
\hline REWS & & 0.21 & 0.11 & 1.86 & .016 & 0.02 & 0.39 \\
\hline Int_1 & & 0.02 & 0.03 & 0.66 & .037 & 0.06 & 0.03 \\
\hline
\end{tabular}

Product terms key:

Int_1: GAMI * REWS

Indirect Effect(s) of $\mathrm{X}$ on $\mathrm{Y}$ :

\begin{tabular}{lcccc} 
& Effect & BootSE & BootLLCI & BootULCI \\
UTIB & 0.24 & 0.06 & 0.14 & 0.34 \\
\hline
\end{tabular}

Level of confidence for all confidence intervals in output: 90

Number of bootstrap samples for percentile bootstrap confidence intervals: 2000

\subsubsection{Mediating Role of Hedonic Benefit in Gamification-Consumer Loyalty Relationship}

In order to test the mediating effect of the hedonic benefit in the gamification-consumer loyalty relationship, the significance of independent variable on the mediator has been tested first. Hence, the results show that gamification tends to have a positive and significant 
relationship with the hedonic benefit, at a value of 0.780 (95\% CI [0.704, 0.857]). Secondly, the significance of the mediator on the dependent variable has also been tested. The Hedonic benefit shows a positive and significant relationship with consumer loyalty at a value of 0.195 (95\% CI $[0.112,0.279])$. Finally, the significant, indirect effect that supports the mediating role of the hedonic benefit, on the gamification-consumer loyalty, i.e., gamification->hedonic benefits->customer loyalty, at a value of $0.152(95 \% \mathrm{CI}[0.570,0.259)(0.152, \mathrm{p}<0.000)$, and with confidence interval of LLCI $=0.57$, ULCI $=0.259$ supports hypothesis 3 . All the details of the process model have been presented in Table 8.

Table: 8: Results of Model 4 for Hypothesis (3)

\begin{tabular}{|c|c|c|c|c|c|c|}
\hline $\begin{array}{l}\mathrm{Y}=\text { CUSTLO } \\
\mathrm{X}=\text { GAMI } \\
\mathrm{M}=\text { HEDB } \\
\text { Sample Size } 240\end{array}$ & & & & & & \\
\hline Outcome & & & HEDB & & & \\
\hline Model & & & Immary & & & \\
\hline $\mathbf{R}$ & R-Sq & MSE & $\mathbf{F}$ & df1 & df2 & p \\
\hline 0.74 & 0.54 & 0.23 & 281.60 & 1.00 & 238.00 & .000 \\
\hline Model & & & & & & \\
\hline & coeff & se & $\mathbf{t}$ & $p$ & LLCI & ULCI \\
\hline Constant & 0.99 & 0.19 & 5.21 & .000 & 0.67 & 1.29 \\
\hline GAMI & 0.78 & 0.05 & 16.78 & .000 & 0.70 & 0.86 \\
\hline Outcome: & & & USTLC & & & \\
\hline Model: & & & ummar & & & \\
\hline $\mathbf{R}$ & R-Sq & MSE & $\mathbf{F}$ & df1 & df2 & p \\
\hline 0.78 & 0.61 & 0.14 & 187.59 & 2.00 & 237.00 & .000 \\
\hline Model & & & & & & \\
\hline & coeff & se & $t$ & $p$ & LLCI & ULCI \\
\hline Constant & 1.14 & 0.15 & 7.34 & .000 & 0.88 & 1.39 \\
\hline GAMI & 0.54 & 0.05 & 10.01 & .000 & 0.45 & 0.62 \\
\hline HEDB & 0.19 & 0.95 & 3.86 & .000 & 0.11 & 0.27 \\
\hline
\end{tabular}

DIRECT AND INDIRECT EFFECTS

Direct effect of $X$ on $Y$

\begin{tabular}{ccccccc}
\hline Effect & $\mathbf{S E}$ & $\mathbf{t}$ & $\mathbf{p}$ & LLCI & ULCI \\
\hline 0.53 & 0.05 & 10.01 & .000 & 0.45 & 0.62 \\
\hline
\end{tabular}

Indirect Effect(s) of $\mathrm{X}$ on $\mathrm{Y}$ :

\begin{tabular}{lcccc}
\hline & Effect & BootSE & BootLLCI & BootULCI \\
\hline HEDB & 0.15 & 0.06 & 0.06 & 0.25 \\
\hline
\end{tabular}

Level of confidence for all confidence intervals in output: 90

Number of bootstrap samples for percentile bootstrap confidence intervals: 2000 


\section{Discussion}

This study was conducted in order to investigate the direct and indirect effects of gamification on consumer loyalty. For this purpose, university students, as a legitimate sample, due to their status as digitally techno savvy individuals, were chosen to represent the idea of gamification success. The results show empirically and substantially, direct and indirect paths, along with reward satisfaction as a conditional variable, moderating the direct effects only. Moreover, the Technology Acceptance Model (TAM) offered the most rationale ground, answering as to why gamification and game mechanics are largely applicable to consumer attitude and loyalty. The study findings help to gain empirically advanced theoretical understanding of the same model.

In this regard, a statistically strong association has been found between gamification and consumer loyalty, as stated in hypothesis 1 . The findings are specifically applicable to the sample under consideration, as the younger techno savvy generation is believed to be particularly intense and habitual users of mobile phones and gaming technology. Moreover, these individuals are believed to be deeply engaged with online experiences, as they frequently and excessively order food using various online applications. In addition to this, these individuals also spend more time accessing internet and social media on a daily basis (Hershatter \& Epstein, 2010). Their desire to maintain social interactions, and co-creating experiences is facilitated through their active involvement in the virtual world (Sarpong et al., 2018). The findings were thus congruent with a variety of extant literature available on gamification, and its outcomes (Hofacker et al, 2016).

The indirect effects, via the utilitarian path, i.e., gamification> utilitarian benefits->consumer loyalty were also found to be significant. Moreover, the mediating effects of these utilitarian benefits seemed to have a rationale relationship. This is so because these functional benefits maybe resorted to as a technique for better engagement, and increased loyalty from a younger audience, who were born in a technological world, with omnipresent utility (Jain \& Dutta, 2019). Hence, it can be asserted that hypothesis 2 is accepted. Moreover, hypothesis 3 , stating that the hedonic benefits mediate the relationship between gamification and consumer loyalty, has also been accepted. The findings, proven the facts of loyalty in todays' digital age, largely depend upon variables such as entertainment, exploration and expression. Therefore, we can assert that these findings are 
congruent with pervious literature written on the discipline (Kusmarini et al., 2020; Oyeniyi, 2011).

Hypothesis 4, stating that the reward satisfaction moderates the relationship between gamification and consumer loyalty, was supported for the current sample. In this accord, the students with higher rewards were the most loyal with the stated gamified applications, and participated in activities for rewards and immediate gratification (Meister \& Willyerd, 2010). Gilbert (2011) recognizes these traits as challenge seeking, wanting to connect, and receiving instant feedback. These tendencies therefore steer their gamification experience towards increased loyalty, and the findings were congruent with the research of Hogberg et al., (2019).

\subsection{Implications and Conclusions}

Viewing the research findings can tell us that users with a highly intense gamification experience are loyal towards the particular online food applications that they have been using. It can also be asserted that the organizations with more gamified elements, can create offerings with great perceived value, so as to outperform their competitors. There are innovative game elements that are incorporated in applications that employ modern marketing concepts for their success factor to click in the desired direction for the business. Companies can empirically employ this practice in the real world, thus influencing the department of marketing to use digital techniques. gamification can make organizations achieve the support that they require for their advertising and monetizing endeavors through their applications, by being a powerful engine for businesses and their goals. Moreover, gamification can be used to build loyalty among consumers and generate sustainable competitive advantage as well. In this regard, the current study findings could benefit practitioners and media students to understand the dynamics of gamification and the success of a company's marketing efforts, as social media-based services implementing gamification, encourage loyalty and improve consumer engagement. Firms can gain access to several opportunities by designing increasingly persuasive computing technology, revolving around entertainment and the game-thinking notion. The gamification system is a deep psychological mechanism, receiving a multidisciplinary attention, so as to enhance the various benefits that it offers, including consumer loyalty for the marketing domain. Subtle, yet powerful ways of persuasive computing, such as games, compel users to buy by exploiting user cognition in a subconscious manner. This unconscious urge to explore and entertain, while shopping 
for various products, make them more loyal to the specific brand employing the idea of gamification.

This study provides valuable insights to companies and marketers considering the concept of gamification to market products and services. Thus, increasing the opportunity for consumers to interact with a particular brand, promote the development of deep relationships between the consumers and the brands, by satisfying the latter with rewards. Using the survey data from the universities in Lahore, and targeting the young audience, this study explains how meeting the monetary and nonmonetary rewards goals tends to encourage the consumers to become loyal towards certain brand, as their points keep on adding with each purchase that they make. The loyalty is achieved while consumers are seeking actual monetary rewards, such as coupons, discount codes, redeemable points, or bonuses in online food delivery applications. Therefore, these findings are valuable empirical input for the existing literature, with reference to the technology acceptance model, enlightening how online gamified applications aim to develop consumer loyalty.

Still in its infancy, the concept of gamification is specifically an emergent concept. This is because there has not been any research published in Pakistan that has thus far linked gamification to the variables revealing its meaningfulness and dimensions. Thus, it holds a position to be recognized by organizations, and desired in many virtues, with continued progression that can be looked forward to.

\subsection{Limitations}

The entire research has been conducted by following certain successful scientific methods of research. However though, the focus has remained on what was important, and therefore, diverted the attention from a few significant aspects that could provide more rigor. While it is clear that the gamification elements are being incorporated by firms in their online applications, there is a need to establish scholarly understanding on how the process actually occurs. Along with the extremely varying implementation patterns, the gamification theory, supported through the empirical data, posits that such gamified applications do not cover an easy approach to fit all sizes (Fuchs, 2014). In the same context, the results obtained from three universities cannot be generalized for all the educational institutions, or the young population using these applications. In order to increase the generalizability of results, the study should be replicated in other contexts as well, particularly with a strong utilitarian interest (e.g. work context or banking apps). In this regard, further research 
can help to analyze the differences between several categories of the industries. Moreover, it must also be noted that individuals not belonging to the millennial era (younger audience) have not been included in the target sample population, whereas they also give preference to online food applications nowadays.

\subsection{Future Research Directions}

Future research revolving around this discipline has the potential to consider gamification with respect to all the major dimensions, so as to determine its strength in predicting consumer loyalty. Other mediators including the aspects of benefits, other than those with hedonic and utilitarian value, or those that are not part of Mathwick et al. (2001) framework can also be considered in this regard. In addition to this, researchers can generalize the results by including samples from various sectors/industries, through different industrial domains such as education, healthcare, and banking. Studying the relationship between gamification and social media networks, along with the influence of a game-full experience on users is another issue that could perhaps be further addressed. Thus, mobilizing the consumer journey concept, as suggested by Lemon and Verhoef (2016), will help to better understand the journey of gamification, and the game-full experience that it provides. Further reward types offered to participant for using the app can also be explored in the studies that might be conducted in the future. 


\section{References}

Alčaković, S., Pavlović, D., \& Popesku, J. (2017). Millennials and Gamification: A model proposal for Gamification application in tourism destination. Marketing, 48(4), 207-214.

Amabile, T. M., \& Kramer, S. J. (2011). The power of small wins. Harvard Business Review, 89(5), 70-80.

Bathmanathan, V., Rajadurai, J., \& Sohail, M. S. (2018). Generational consumer patterns: A document analysis method. Global Business and Management Research, 10(3), 958-970

De Gieter, S., \& Hofmans, J. (2015). How reward satisfaction affects employees' turnover intentions and performance: an individual differences approach. Human Resource Management Journal, 25(2), 200-216.

Deterding, S. (2012). Gamification: designing for motivation. Interactions, 19(4), 14-17.

Faiola, A., Newlon, C., Pfaff, M., \& Smyslova, O. (2013). Correlating the effects of flow and telepresence in virtual worlds: Enhancing our understanding of user behavior in game-based learning. Computers in Human Behavior, 29(3), 1113-1121.

Fuchs, M. (2014). Gamification as twenty-first-century ideology. Journal of Gaming E Virtual Worlds, 6(2), 143-157.

Gatautis, R., Vitkauskaite, E., Gadeikiene, A., \& Piligrimiene, Z. (2016). Gamification as a mean of driving online consumer behaviour: SOR model perspective. Engineering Economics, 27(1), 90-97.

Gilbert, J. (2011). The Millennials: A new generation of employees, a new set of engagement policies. Ivey Business Journal, 75(5), 26-28.

Hamari, J., \& Koivisto, J. (2015). Why do people use gamification services? International Journal of Information Management, 35(4), 419-431.

Hamari, J., Koivisto, J., \& Sarsa, H. (2014, January). Does Gamification work? A literature review of empirical studies on Gamification. In 2014, 47th Hawaii international conference on system sciences (pp. 3025-3034). 
Helmefalk, M. (2019). An interdisciplinary perspective on Gamification: Mechanics, psychological mediators and outcomes. International Journal of Serious Games, 6(1), 3-26.

Hershatter, A., \& Epstein, M. (2010). Millennials and the world of work: An organization and management perspective. Journal of business and psychology, 25(2), 211-223.

Higgins, E. T. (2006). Value from hedonic experience and engagement. Psychological review, 113(3), 439.

Hofacker, C. F., De Ruyter, K., Lurie, N. H., Manchanda, P., \& Donaldson, J. (2016). Gamification and mobile marketing effectiveness. Journal of Interactive Marketing, 34, 25-36.

Högberg, J., Ramberg, M. O., Gustafsson, A., \& Wästlund, E. (2019). Creating brand engagement through in-store gamified customer experiences. Journal of Retailing and Consumer Services, 50 (Sept.), 122-130.

Holbrook, M. B. (2006). Consumption experience, consumer value, and subjective personal introspection: An illustrative photographic essay. Journal of business research, 59(6), 714-725.

Hsu, C. L., \& Lin, J. C. C. (2016). Effect of perceived value and social influences on mobile app stickiness and in-app purchase intention. Technological Forecasting and Social Change, ISSN 0040-1625, 108(July), 42-53.

Hung, H. Y. (2014). Attachment, identification, and loyalty: Examining mediating mechanisms across brand and brand community contexts. Journal of Brand Management, 21(7), 594-614.

Huotari, K., \& Hamari, J. (2012, October). Defining Gamification: a service marketing perspective. In Proceeding of the 16th international academic MindTrek conference (pp. 17-22).

Huotari, K., \& Hamari, J. (2017). A definition for Gamification: anchoring Gamification in the service marketing literature. Electronic Markets, 27(1), 21-31.

Hwang, J., \& Choi, L. (2020). Having fun while receiving rewards? Exploration of Gamification in loyalty programs for consumer loyalty. Journal of Business Research, ISSN 0148-2963, 106(Jan), 365-376. 
Jain, A., \& Dutta, D. (2019). Millennials and Gamification: Guerilla Tactics for Making Learning Fun. South Asian Journal of Human Resources Management, 6(1), 29-44.

Jin, C. H. (2016). The effects of mental simulations, innovativeness on intention to adopt brand application. Computers in Human Behavior, 54(Jan), 682-690.

Koivisto, J., \& Hamari, J. (2019). The rise of motivational information systems: A review of Gamification research. International Journal of Information Management, 45(April), 191-210.

Kusmarini, R. A., Sumarwan, U., \& Simanjuntak, M. (2020). The effect of atmosphere perception, perceived value, and hedonic value on consumer loyalty through the service quality of warunk upnormal. Indonesian Journal of Business and Entrepreneurship (IJBE), 6(1), 53-53.

Lamphun, R. N., Lamphun, P. N., Patompak, P., \& Chitpong, J. (2019). Gamification's effect in Social Media on CSR activities. International Scientific Journal of Engineering and Technology (ISJET), 3(1), 25-30.

Landers, R. N., Bauer, K. N., \& Callan, R. C. (2017). Gamification of task performance with leaderboards: A goal setting experiment. Computers in Human Behavior, ISSN 0747-5632, 71(June), 508-515.

Leclercq, T., Poncin, I., \& Hammedi, W. (2020). Opening the black box of gameful experience: Implications for Gamification process design. Journal of Retailing and Consumer Services, 52(Jan), 101882.

Lemon, K. N., \& Verhoef, P. C. (2016). Understanding consumer experience throughout the consumer journey. Journal of Marketing, 80(6), 69-96.

Lucassen, G., \& Jansen, S. (2014). Gamification in Consumer MarketingFuture or Fallacy? Procedia-Social and Behavioral Sciences, ISSN 18770428, 148(Aug), 194-202.

Luk, S. T., \& Yip, L. S. (2008). The moderator effect of monetary sales promotion on the relationship between brand trust and purchase behaviour. Journal of Brand Management, 15(6), 452-464.

Mathwick, C., Malhotra, N., \& Rigdon, E. (2001). Experiential value: conceptualization, measurement and application in the catalog and Internet shopping environment 2 . Journal of Retailing, 77(1), 39-56. 
Meister, J. C., \& Willyerd, K. (2010). Mentoring millennials. Harvard Business Review, 88(5), 68.

Oliver, R. L. (1999). Whence consumer loyalty? Journal of Marketing, 63(4_suppl1), 33-44.

Oyeniyi, O. (2011). Sales promotion and consumer loyalty: A study of Nigerian telecommunication industry. Journal of Competitiveness, 3(4), 66-77.

Pallas, F., Mittal, V., \& Groening, C. (2014). Allocation of resources to customer satisfaction and delight based on utilitarian and hedonic benefits. Journal of Research in Marketing, 2(1), 106-112.

Pavlov, G., Maydeu-Olivares, A., \& Shi, D. (2021). Using the standardized root mean squared residual (SRMR) to assess exact fit in structural equation models. Educational and Psychological Measurement, 81(1), 110-130.

Perryer, C., Celestine, N. A., Scott-Ladd, B., \& Leighton, C. (2016). Enhancing workplace motivation through Gamification: Transferrable lessons from pedagogy. The International Journal of Management Education, 14(3), 327-335.

Ryan, R. M., \& Deci, E. L. (2000). Self-determination theory and the facilitation of intrinsic motivation, social developments, and wellbeing. American Psychologist, 55(1), 68.

Sailer, M., Hense, J. U., Mayr, S. K., \& Mandl, H. (2017). How Gamification motivates: An experimental study of the effects of specific game design elements on psychological need satisfaction. Computers in Human Behavior, 69(April), 371-380.

Seaborn, K., \& Fels, D. I. (2015). Gamification in theory and action: A survey. International Journal of human-computer studies, 74(Feb), 14-31.

Shen, L., Hsee, C. K., \& Talloen, J. H. (2019). The Fun and Function of Uncertainty: Uncertain Incentives Reinforce Repetition Decisions. Journal of Consumer Research, 46(1), 69-81.

Sigala, M. (2015). Gamification for crowdsourcing marketing practices: Applications and benefits in tourism. Advances in Crowdsourcing, 129-145. 
Smith, J. B., \& Colgate, M. (2007). Consumer value creation: a practical framework. Journal of Marketing Theory and Practice, 15(1), 7-23.

Stein, J. (2013). Millennials: The me me me generation. Time Magazine, 20, $1-8$.

Stock, R. M., Oliveira, P., \& von Hippel, E. (2015). Impacts of hedonic and utilitarian user motives on the innovativeness of user-developed solutions. Journal of Product Innovation Management, 32(3), 389-403.

Temnyalov, E. (2019). Points mechanisms and rewards programs. Journal of Economics \& Management Strategy, 28(3), 436-457.

Underwood, R. L., \& Klein, N. M. (2002). Packaging as brand communication: effects of product pictures on consumer responses to the package and brand. Journal of Marketing Theory and Practice, 10(4), 58-68.13167.

Heijden, H. (2004). User acceptance of hedonic information systems. MIS Quarterly, 28(4), 695-704.

Vargo, S. L., \& Lusch, R. F. (2016). Institutions and axioms: an extension and update of service-dominant logic. Journal of the Academy of Marketing Science, 44(1), 5-23.

Wang, E. S. T. (2017). Different effects of utilitarian and hedonic benefits of retail food packaging on perceived product quality and purchase intention. Journal of Food Products Marketing, 23(3), 239-250.

Witt, M., Scheiner, C. W., \& Robra-Bissantz, S. (2011, October). Gamification of online idea competitions: insights from an explorative case. In GI-Jahrestagung (p. 392).

Zhao, F., \& Guo, D. (2019, July). Rewards in Gamification. In International Conference on Human-Computer Interaction (pp. 453-462). Springer, Cham. 


\section{Annexure}

\section{Survey Questionnaire}

\section{Dear Sir/Madam!}

This survey is being conducted to analyze your gamification experience with food delivery applications. Your anonymity will be strictly retained. Your time, cooperation and honest feedback is highly appreciated.

\begin{tabular}{|l|l|l|}
\hline $\begin{array}{l}\text { Are you a frequent user of gaming apps like McDelivery } \\
\text { and FoodPanda for bonus points on purchase of food? }\end{array}$ & Yes ( ) & No ( ) \\
\hline
\end{tabular}

If yes, how frequent? ( )To a small extent ( )To a moderate extent

( )To a great extent

\section{General Information:}

a) Gender: Male ( ) Female ( )

b) Age: ( ) below $20 \quad$ ( )20-22 ( )23-25

c) Household Income: ( ) 30,000 - 50,000 ( ) 51,000 - 70,000

( ) 71,000-90,000 ( ) above 90,000

\begin{tabular}{|c|c|c|c|c|c|c|}
\hline & $\begin{array}{l}\text { Keeping in mind the above mentioned } \\
\text { application(s) (McDelivery \& FoodPanda) } \\
\text { please indicate your Gamification } \\
\text { experience. }\end{array}$ & 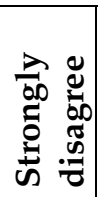 & 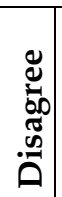 & 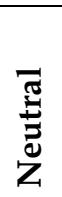 & 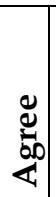 & 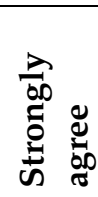 \\
\hline & $\begin{array}{l}\text { 1) The content motivates me and makes me } \\
\text { want to engage more for bonus points }\end{array}$ & & & & & \\
\hline & $\begin{array}{l}\text { 2) The flow and process of this app is easy to } \\
\text { learn }\end{array}$ & & & & & \\
\hline & $\begin{array}{l}\text { 3) This app is engaging which makes me } \\
\text { want to continue playing. }\end{array}$ & & & & & \\
\hline & $\begin{array}{l}\text { 4) I feel like I am a part of the content and } \\
\text { game }\end{array}$ & & & & & \\
\hline & $\begin{array}{l}\text { 5) The prize/ reward system motivates me to } \\
\text { complete the task }\end{array}$ & & & & & \\
\hline & $\begin{array}{l}\text { 6) The content and game system makes me } \\
\text { want to share it with others. }\end{array}$ & & & & & \\
\hline 3. & $\begin{array}{l}\text { Keeping in mind the same application(s), } \\
\text { please rate the following questions which } \\
\text { best indicates your consumer loyalty } \\
\text { towards the application (s) }\end{array}$ & & & & & \\
\hline
\end{tabular}




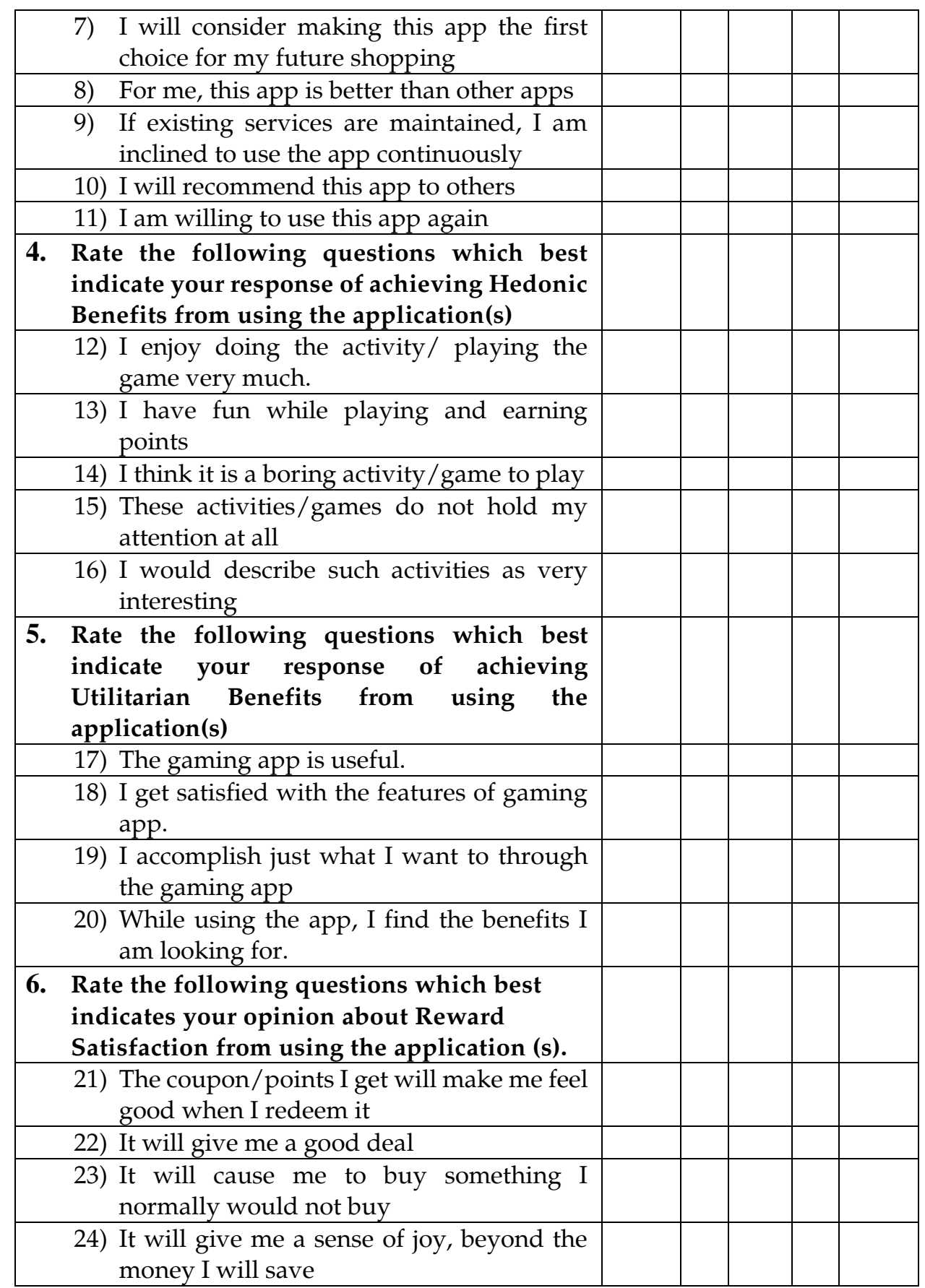

Thank You 